\title{
Monitoring Water Transparency and Diver Visibility in Ports and Harbors Using Aircraft Hyperspectral Remote Sensing
}

Charles C. Trees ${ }^{*}$, Paul W. Bissett ${ }^{\mathrm{b}}$, Heidi Dierssen ${ }^{\mathrm{c}}$, David D. R. Kohler ${ }^{\mathrm{b}}$ Mark A. Moline ${ }^{\mathrm{d}}$, James L. Mueller ${ }^{\mathrm{a}}$, Richard E. Pieper ${ }^{\mathrm{e}}$, Michael S. Twardowski ${ }^{\mathrm{f}}$, J. Ronald V. Zaneveld ${ }^{\mathrm{g}}$

${ }^{a}$ Center for Hydro-Optics and Remote Sensing, San Diego State Univ., 6505 Alvarado Road, Suite 206, San Diego, CA, USA 92120;

${ }^{\mathrm{b}}$ Florida Environmental Research Institute, 4807 Bayshore Blvd., Suite 101, Tampa, FL, USA 33611;

'Department of Marine Sciences, Univ. of Connecticut, 1080 Shennecossett Road, Groton, CT, USA 06340;

dBiological Sciences Dept, California Polytechnic State Univ., 1 Grand Ave, San Luis Obispo, CA, USA 93407;

'Oceans Studies Institute, Long Beach California State Univ., Fish Harbor, 820 S. Seaside Ave., Terminal Island, CA, USA 90731;

${ }^{f}$ WET Labs, Inc., Dept. Research, 165 Dean Knauss Dr., Narragansett, RI, USA 02882;

${ }^{g}$ WET Labs, Inc., P.O. Box 518, Philomath, OR, USA 97370

Diver visibility analyses and predictions, and water transparency in general, are of significant military and commercial interest. This is especially true in our current state, where ports and harbors are vulnerable to terrorist attacks from a variety of platforms both on and below the water (swimmers, divers, AUV's, ships, submarines, etc.). Aircraft hyperspectral imagery has been previously used successfully to classify coastal bottom types and map bathymetry and it is time to transition this observational tool to harbor and port security. Hyperspectral imagery is ideally suited for monitoring small-scale features and processes in these optically complex waters, because of its enhanced spectral (1-3 $\mathrm{nm}$ ) and spatial (1-3 meters) resolutions. Under an existing NOAA project (CICORE), a field experiment was carried out (November 2004) in coordination with airborne hyperspectral ocean color overflights to develop methods and models for relating hyperspectral remote sensing reflectances to water transparency and diver visibility in San Pedro and San Diego Bays. These bays were focused areas because: (1) San Pedro harbor, with it's ports of Los Angeles and Long Beach, is the busiest port in the U.S. and ranks $3^{\text {rd }}$ in the world and (2) San Diego Harbor is one of the largest Naval ports, serving a diverse mix of commercial, recreational and military traffic, including more than 190 cruise ships annual. Maintaining harbor and port security has added complexity for these Southern California bays, because of the close proximity to the Mexican border. We will present in situ optical data and hyperspectral aircraft ocean color imagery from these two bays and compare and contrast the differences and similarities. This preliminary data will then be used to discuss how water transparency and diver visibility predictions improve harbor and port security.

Keywords: Ports, harbors, security, water transparency, diver visibility, optical properties, hyperspectral, aircraft data, in situ data, and validation.

\section{INTRODUCTION}

The ability to predict water visibility would be a very beneficial product for the recreational and commercial diving industry in Southern California for planning dive trips (dates and destinations). Of more importance, however, are the port security implications of diver visibility in and around major commercial and military harbor complexes. San Diego Bay and San Pedro Bay (including Long Beach and Los Angeles Harbors) contain naval and commercial shipping 
facilities that are vital to California and U.S. national economies and defense and are vulnerable to surreptitious attack by diver-planted explosive devices. In addition, water clarity is important when designing optical scanning systems for monitoring the hulls of the various ships passing though these busy ports. The performance of LASER Line Scanners (LLS) is drastically affected by water clarity. For example, during a NOAA experiment in clear Hawaiian waters, a LLS positioned $45 \mathrm{~m}$ from the seafloor had a swath width of $65 \mathrm{~m}$ and a pixel resolution of $3 \mathrm{~cm}$. In contrast, to achieve similar performance in the turbid waters of Boston Harbor, the LLS had to be $3 \mathrm{~m}$ off the bottom and had only a $4 \mathrm{~m}$ swath width and $0.2 \mathrm{~cm}$ pixel size. For the initial design and then placement of these optical systems for rapid and efficient scanning of ship hulls requires (1) knowledge of the range in optical properties found in various ports and harbors, (2) deployment of optical sensors to monitor these properties and (3) development of models to predict these changes. Water clarity (or diver-visibility), and its spatial and temporal variability, are important factors in port security, and new, robust methods for monitoring and predicting it would be a valuable contribution to regional and national Homeland Security capability.

San Diego and San Pedro Bays are important areas to study because of their large volume of commercial and military traffic and the close proximity to the Mexican border (10 and 106 miles, respectively). San Diego harbor is one of the largest military ports with one third of the US Navy fleet using it as homeport. San Diego Bay is 14 miles long and is considered as one of the finest natural harbors in the world, affording excellent protection in most weather conditions. The ports of Los Angeles and Long Beach are located in San Pedro Bay and are protected by a man-made breakwater. They occupy over 10,500 acres of land and water and are the top two busiest ports in the United States and, if combined, rank $3^{\text {rd }}$ in the world. A man-made island, Terminal Island, sits in the center of the complex and is part of both ports. In 2003 the number of commercial ships arriving at Long Beach and Los Angeles harbors was 5,696, an increase of 6\% over 2002. These two bays in southern California are very important to the United States economy and national defense.

Under a partnership with the Center for Integrative Coastal Observations, Research and Education (CICORE), we participated in a field experiment (14-21 Nov 2004) to combine in situ measurements of physical, biogeochemical and optical properties with high-resolution hyperspectral ocean color imagery, measured from aircraft, to map the patterns of diver visibility and suspended particulate concentrations near and within San Diego and San Pedro Bays, the sites of two major port complexes of vital economic and military importance in southern California. CICORE was established in 2002 with funding from the NOAA Coastal Observation Technology System (COTS) in an effort to create a coastal monitoring and research observatory network for the entire 1200 miles of the California coast. CICORE addresses a variety of challenges to coastal environmental quality, including watershed alteration, shoreline erosion, chemical contamination of food webs, depletion of fish stocks, toxic plankton blooms, marine-borne pathogens, and the rapid invasion of coastal and estuarine waters by non-indigenous species.

The primary objective of our study was to develop methods for using in situ monitoring of inherent optical properties (IOP; absorption, scattering and attenuation), and semi-empirical models relating IOP to hyperspectral remote sensing reflectance, to derive distributions of the beam attenuation coefficient $c(532)$, from which diver visibility could be derived using existing models. An eventual goal would be to use the information from a series of such experiments to tune and constrain a predictive model of IOP-derived diver visibility and sediment load driven by circulation and vertical mixing within a port (as driven by tidal and wind forcing, and in some cases freshwater influx). A secondary objective of the research was to apply information derived from relationships between IOP and suspended particulates to monitor the health of ecosystems in marine habitats near and within these two embayments. Issues of concern to regional coastal zone managers, for example, are the impacts and consequences when raw sewage and/or heavy loads of suspended sediments may be injected into these habitats during periods of heavy rainfall and runoff.

\section{METHODOLOGY}

The first CICORE study was in November 2004 and was at the end of a larger one-month field campaign to acquire hyperspectral imagery and collect ground-truth data from eight selected coastal areas and bays along California. For the San Pedro Bay and surrounding areas we participated with our colleagues at Ocean Studies Institute, California State University Long Beach, and used one of their coastal research vessels. A total of seventeen stations were occupied during the 2-day field campaign (14-15 Nov 04); only those ten stations within and around San Pedro Bay are plotted in Figure 1. At these stations vertical CTD-IOP cast were made (WET Labs AC-9, absorption and attenuation meter), concurrently with near surface $(5 \mathrm{~cm})$ measurements of upwelling radiance, upwelling irradiance and above water solar 
irradiance, using a hyperspectral radiometer (Satlantic Hyper-Pro II). This optical data is required to calibrate and validate the aircraft radiance measurements taken during the overflights. Bucket samples were also collected and processed for the determination of colored dissolved organic material (CDOM) and particulate spectral absorptions, and HPLC measured pigment concentrations.

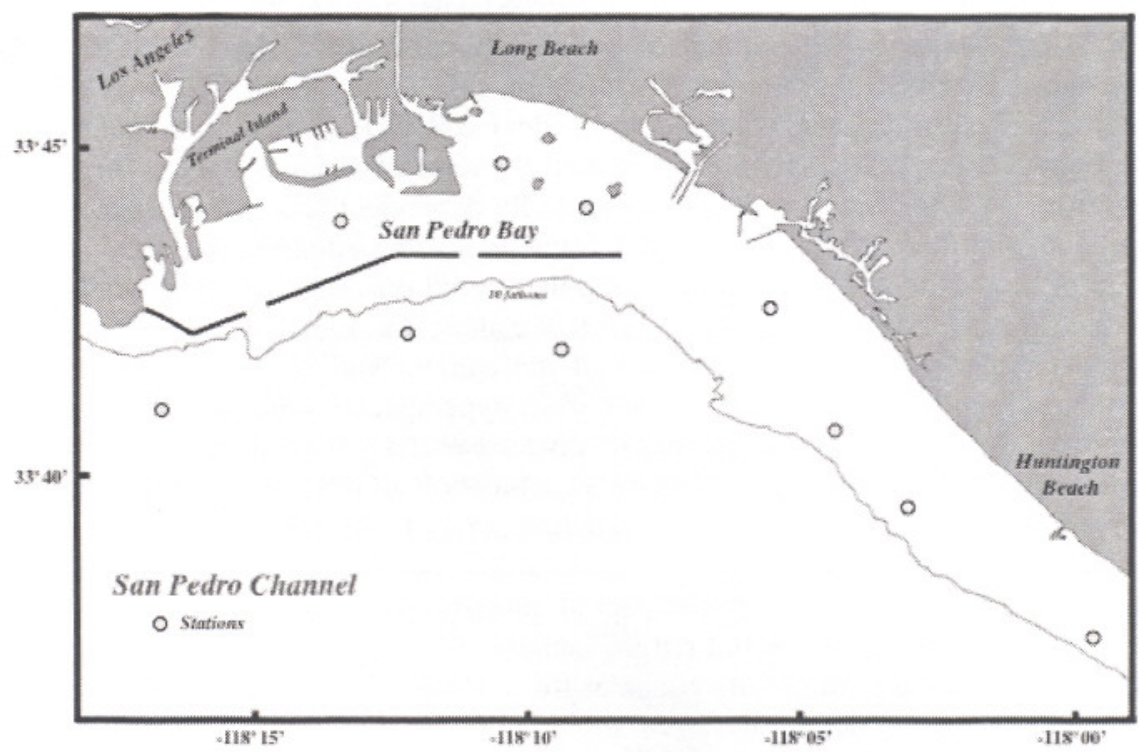

Figure 1. Station positions during the Fall 2004 CICORE field compaign.

For the field campaign in San Diego Bay a more extensive optical sampling strategy was done (Figure 2). Twenty-four stations were occupied (17-22 Nov 04), collecting similar bio-optical data as described for the San Pedro Bay stations. In addition, between stations an undulating IOP and bio-optical sensing system (WET Labs DOLPHIN; Diving OppticaL Profiler and High-speed Integration Network) was towed. The DOLPHIN was equipped with a suite of bio-optical sensors (backscattering meter and fluorescence meters, two AC-9 sensors, and Scattering and Absorption Meter (SAM $\left.{ }^{1}\right)$ as well as a CTD. As we approached a station the DOLPHIN was brought to the surface and then performed a vertical profile as the boat reduced speed. While on station it continued to operate providing temporal variability in bio-optical

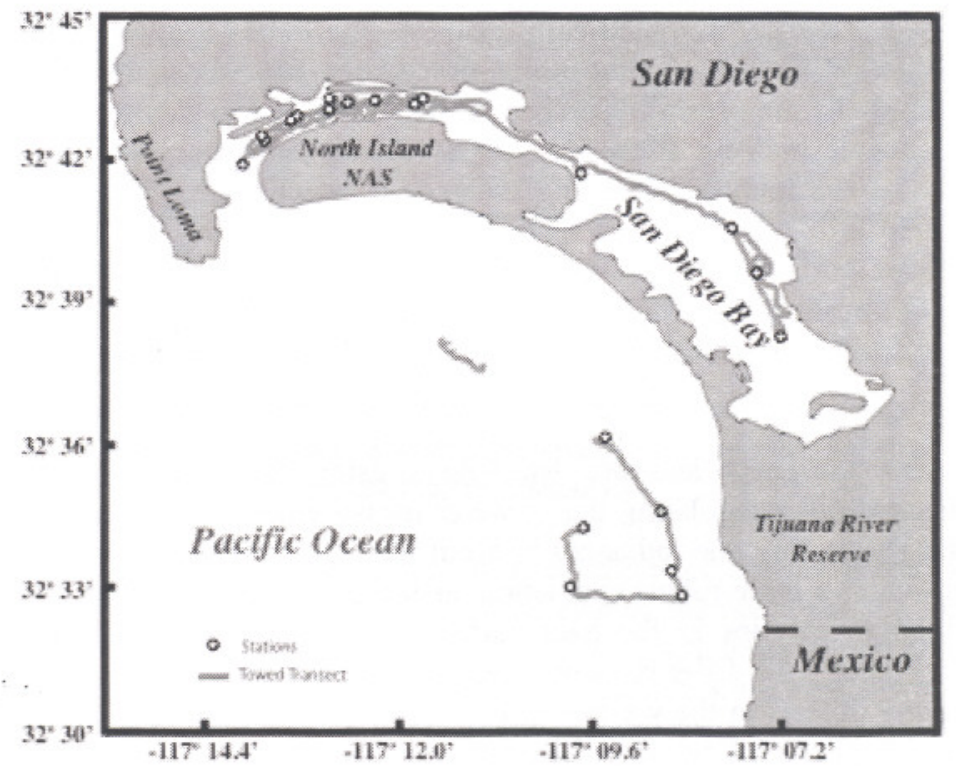

Figure 2. Station positions and towed vehicle coverage during the Fall 2004 CICORE field campaign. 
properties at the bottom of the profile. As can be seen in Figure 2, the upper San Diego Bay area was extensively sampled with the DOLPHIN to map the near surface optical properties during the field experiments and aircraft overflights.

Remotely sensed hyperspectral data was collected with the Portable Hyperspectral Imager for Low-Light Spectroscopy 2 (PHILLS 2) instrument ${ }^{2}$. This sensor is the product of collaborations between the Florida Environmental Research Institute (FERI) and the Naval Research Laboratory, Washington, DC. The PHILLS 2 is an aircraft mounted, pushbroom type sensor, utilizing a two dimensional charge coupled device (CCD) camera to collect the spectral information along a single line on the ground perpendicular to the direction the aircraft is traveling. As the aircraft moves forward along its trajectory, the sensor's CCD camera captures the spatially dependent spectral information one frame at a time across a thin swath of ground, and thus, as each along-track frame is assembled the image cube is built. Integration time of the sensor is a function of the frame rate of the camera and the spatial resolution in the cross-track is dependent upon the sensor's lens, CCD dimensions, and aircraft altitude. While the along-track spatial resolution is a function of the lens and altitude also, it is more dependent on the frame rate of the camera and speed of the aircraft. The sensor was calibrated with a $17 \mathrm{~mm}$ lens using a frame rate of $30 \mathrm{~Hz}$ to collect hyperspectral data from $400 \mathrm{~nm}$ to $960 \mathrm{~nm}$ with a band spacing of $4.6 \mathrm{~nm}$. This equated to a 3 meter ground sample distance and a $1.9 \mathrm{~km}$ swath at flight altitude and speed of 3,000 meters and 150 knots. Flight lines were generated for each location and date range to reduce the probability of sun glint contamination while maintaining nearly constant illumination across the scene.

What distinguishes this instrument from other hyperspectral push-broom sensors is that the sensor was designed specifically for oceanic and near-shore hyperspectral remote sensing. Capturing coastal optical signals from an airborne platform poses design challenges that are not usually consider for terrestrially focused systems. The primary challenge is signal sensitivity. Imaging over optically deep waters and at high altitudes, the atmosphere makes up the majority of the observed signal ( $\sim 90-100 \%)$. This combined with the nonlinear attenuation properties of water requires a sensor to have a high degree of sensitivity in order to properly map the water's subtle spectral characteristics. In the coastal environment, this is compounded by the relatively bright returns from shallow areas, where its high albedo makes the bottom visible. The challenge is to resolve not only shallow and deep water signals effectively without saturating the sensor's CCD, but to also not saturate while imaging adjacent bright land or clouds. To address this, the PHILLS 2 was purposely built around a high dynamic range camera to allow the flexibility in capturing this dynamic and complex environment ${ }^{3}$.

\section{DATA}

The various in situ optical data is used to radiometrically calibrate the PHILLS 2 sensor, as well as develop robust atmospheric correction algorithms. Automated processing procedures have been developed to enhance this time consuming procedure. An example of the in situ hyperspectral data collected in San Diego Bay is shown in Figure 3. The top curve is the solar irradiance incident at the surface, where as the low curve represents the remote sensing reflectance, which is calculated as the ratio of upwelling radiance to downwelling irradiance and has no units. The upwelling radiance was measured at $5 \mathrm{~cm}$ below the surface and was propagated to and through the surface using a radiative transfer numerical model that computes radiance distributions and related quantities (irradiances, reflectances, diffuse attenuation functions, etc.) in the ocean (HYDROLIGHT; Sequoia Scientific, Inc). An interesting feature in the remote sensing reflectance spectrum is the peak centered around $680 \mathrm{~nm}$, the in vivo fluorescence signal of living phytoplankton.

A comparison was made between San Diego and San Pedro Bays, using data collected with the in situ hyperspectral radiometer (Hyper Pro II). Instead of extrapolating the in water measurements to above the surface as was shown in Figure 3 for one station in San Diego Bay, the radiances at $5 \mathrm{~cm}$ were normalized to the incident solar flux above the water surface $\left(\operatorname{Ed}\left(0^{+}\right)\right.$. This provides a more robust evaluation, as the uncertainty inherent in propagating the upwelling radiance and the unknown inhomogeneities in the near surface optical properties are not included in this optical comparison. As can be seen in Figure 4 the differences between the two Bays are striking. Any type of human or optical detection scenarios for identifying objects in the water will have varying degrees of success, especially in the 450-550 $\mathrm{nm}$ ranges. Obviously, at least for this sampling period, the in-water optical constituents were different for the two Bays and may represent the variability associated with the two drainage systems that feed into these areas. 


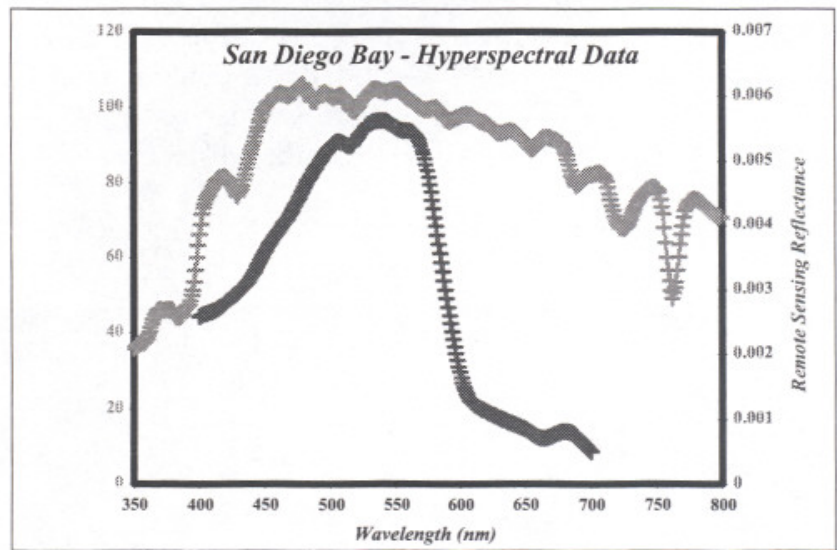

Figure 3. Hyperspectral data collected in San Diego Bay using the Hyper-Pro II instrument. The red curve is the downwelling solar irradiance in $W^{-2}$ and the blue curve is remote sensing reflectance.

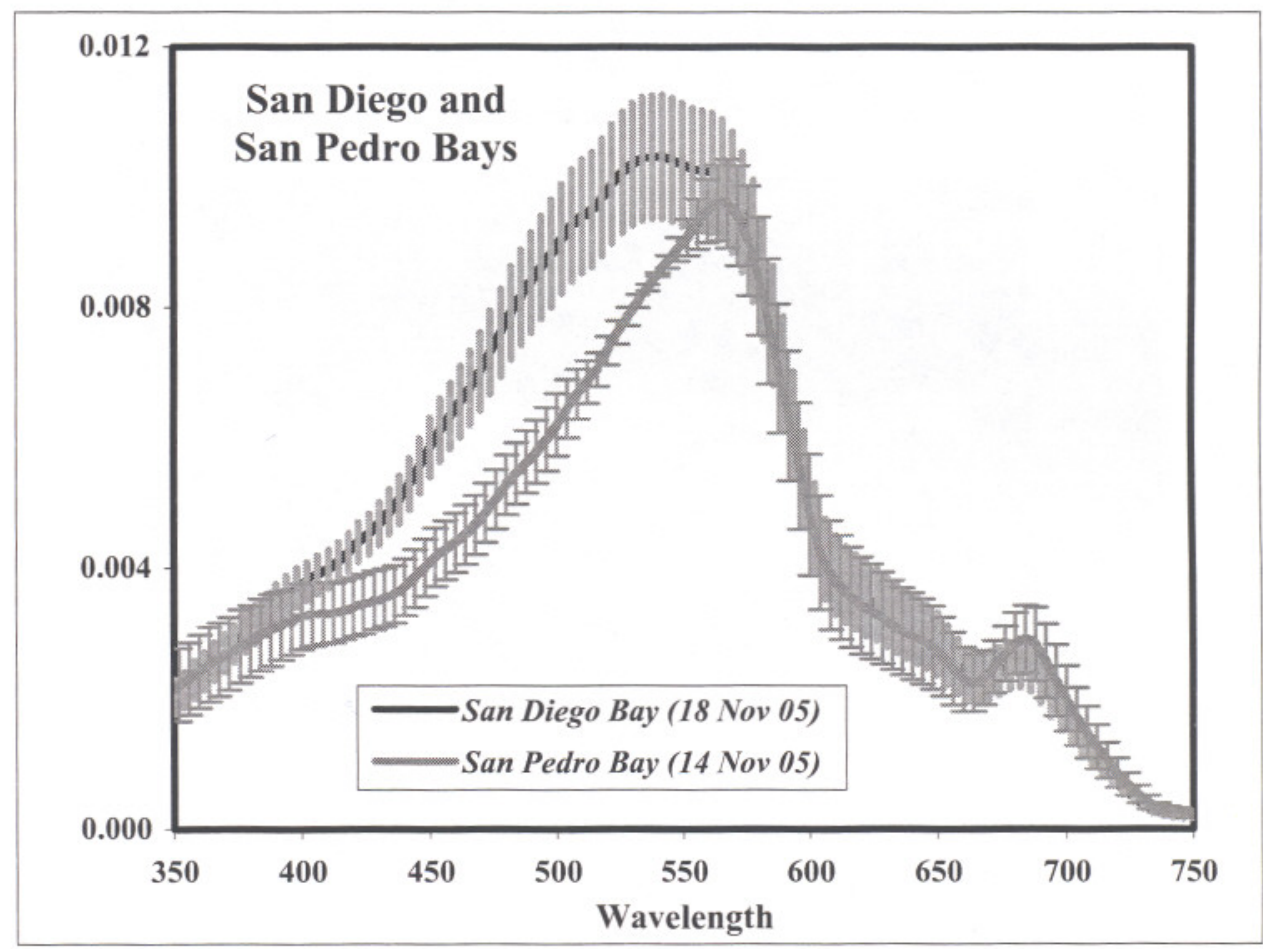

Figure 4. Hyperspectral data collected in San Diego and San Pedro Bays using the Hyper-Pro II radiometer. These are averaged spectra with standard deviations. The black curve is for San Diego Bay (7 stations) and red is San Pedro Bay (3stations).

The IOP data collected during the DOLPHIN tows is used to describe the horizontal and vertical variability in these properties during the San Diego Bay field exercise. A contour map of the beam attenuation coefficient at $650 \mathrm{~nm}$, as measured by the SAM is plotted in Figure 5A. Elevated c $(650)$ values were found in the north portion of the San Diego Bay and decrease significantly towards the mouth of the bay. In addition, somewhat lower values were found towards the eastern side of the North San Diego Bay.

The ability to accurately estimate and predict the visibility of objects in the water is an important parameter for a variety of military and commercial applications. In typical ambient illumination this visibility of objects is not limited by the 
angle they subtend, but by the contrast reduction. Algorithms have been developed relating diver visibility to beam attenuation with the accuracy of these retrievals having an average error of less than $10 \%$ in a wide variety of coastal and inland waters ${ }^{4}$. Using $\mathrm{c}(650)$ data from the SAM on the DOLPHIN a contour map of diver visibility was generated (Figure 5B). Obviously, it has similar features as Figure 5A, as it was derived from the $\mathrm{c}(650)$ measurements, but it is inversely related with high attenuations having the lowest diver visibility distances.
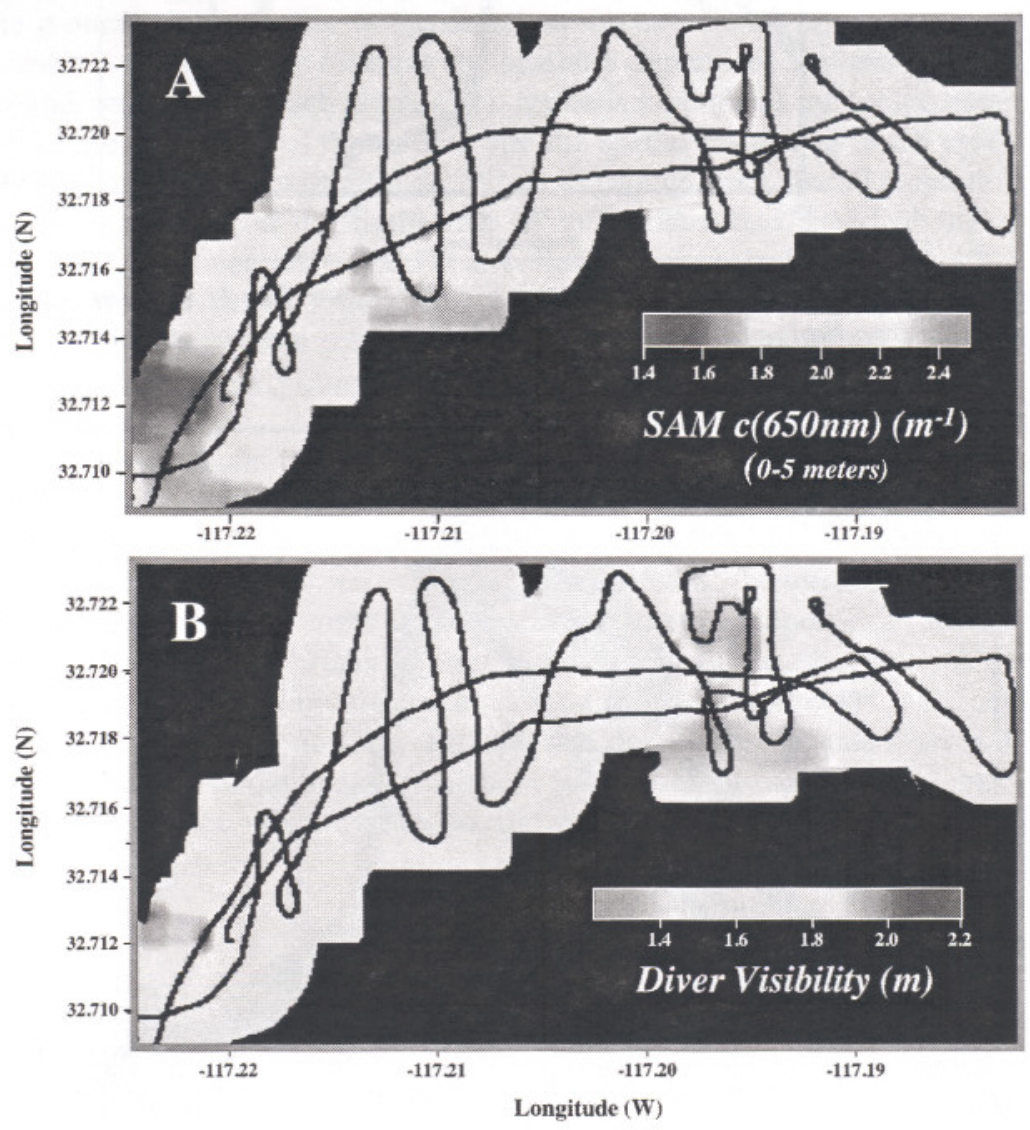

Figure 5. Attenuation coefficient at $650 \mathrm{~nm}$ (A) measured with the SAM during tows with the DOLPHIN (lines) in the North San Diego Bay. Using a relationship between c(650) and diver visibility a contour was generated on the same area (B). Data was limited from the near surface to 5 meters depth. 


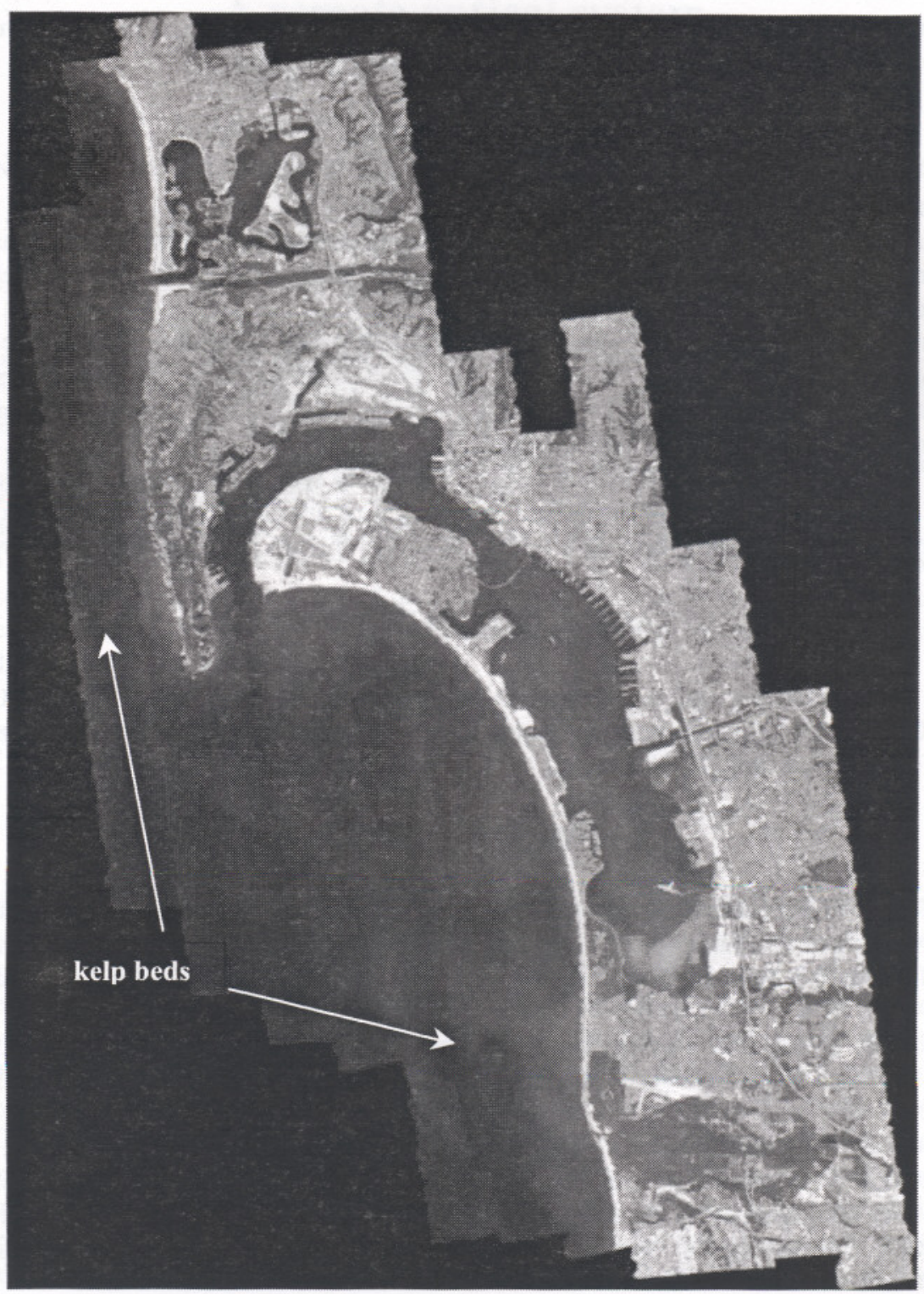

Figure 6. PHILLS Hyperspectral image of San Diego Bay and surrounding areas collected on 18 Nov 2004. The image has been color enhanced and processed though Phase 1.

The hyperspectral PHILLS aircraft data for the San Diego Bay is shown in Figure 6. This imagery has been correct for Phase I processing and has been artificially color enhanced to bring out some of the salient features. Phase I processing schedule includes initial application of the laboratory calibration and atmospheric correction and a preliminary geocorrection. Phase 2 of the PHILLS processing, currently being performed, investigates the calibration accuracy by evaluating the possible occurrence of aberrations during deployment. This is done in concert with the Phase 2 atmospheric correction, which uses the visible spectral lines in the atmosphere to ascertain the stability of the laboratory calibration. Finally, orthrectication is performed to produce a geographic accuracy on the order of 0.5 meters. Once the atmospheric contribution to the PHILLS signal has been removed then the remaining signal is compared to the remote sensing reflectance measurements (e.g. Fig 4) collected during the various ground-truth field experiments.

From the Figure 6 the kelp beds (Black areas) off Point Loma and the Tijuana River Reserve can be seen. In addition, there is a lot of optical variability seen in the San Diego Bay and some of this structure maybe be related to imaging the 
bottom with this imagery. The data resolution for this image is 3 meters, although 0.5 -meter resolution digital camera Red-Green-Blue (RGB) images were also collected and will be analyzed in the future.

\section{DISCUSSION}

Some general and preliminary observations may be made from this data:

1. San Diego and San Pedro Bays, which are important commercial and military centers have a large range of variability in water clarity. This optical variability should have a direct impact the design and deployment of optical scanning systems for the detection of underwater objects.

2. Based on the limited "ground-truth" observations acquired in late November 2004, these two bays have very distinct optical properties. The spatial and temporal extent and significance of these signature differences are presently unknown, but are under study. A concerted effort would be required, with optical moorings and additional shipboard and aircraft measurements, to monitor and map such differences.

3. Because of the juxtaposition of significant optical variability with related military and commercial interests, these two bays provide an ideal area for the development and testing of optical monitoring and prediction methods that could be extended to other bays and harbors throughout the U.S, and to foreign ports and harbors as well.

\section{ACKNOWLEDGEMENTS}

Support for the in situ data collection and the aircraft overflights was provided by the NOAA Coastal Observation Technology System (COTS, http://www.csc.noaa.gov/cots/) under a partnership with the Center for Integrative Coastal Observations, Research and Education (CICORE, http://cicore.mlml.calstate.edu/).

\section{REFERENCES}

1. M. S. Twardowski, J. R. V. Zaneveld, C. M. Moore, J. Mueller, C. Trees, O. Schofield, S. Freeman, T. Helble, and G. Hong. 2005. Diver visibility measured with a compact scattering-attenuation meter (SAM) compatible with AUVs and other small deployment platforms. Defense and security symposium, SPIE, Conf 5708, Orlando, FL 28 Mar - 1 Apr 05.

2. C. C. Davis, J. Bowles, R. A Leathers, D. Korwan. T. V. Downes, W. A. Snyder, W. J. Rhea, W. Chen, J. Fisher, W. P. Bissett, and R. A. Reisse. 2002. Ocean PHILLS hyperspectral imager: design, characterization, and calibration. Optics Express 10: 210- 221.

3. W. P. Bissett, S. DeBra, M. Kadiwala, D. D. R. Kohler, C. D. Mobley, R. G. Steward, A. D. Weidemann, C. O. Davis, J. Lillycrop, and R. L. Pope. 2005. Development, validation, and fusion of high-resolution active and passive optical imagery. Defense and security symposium, SPIE, Conf 5809, Orlando, FL 28 Mar - 1 Apr 05.

4. J. R. V. Zaneveld and W. S. Pegau. 2003. Robust underwater visibility parameter. Optics Express, 11: 2997-3,009.

* ctrees@chors.sdsu.edu; phone 1619 594-2241; fax 1619 594-8670 